\title{
A Prospective Proteomic-Based Study for Identifying Potential Biomarkers for the Diagnosis of Cholangiocarcinoma
}

\author{
Yuan Shi • Xiaxing Deng • Qian Zhan • Baiyong Shen • \\ Xiaolong Jin • Zhecheng Zhu • Hao Chen • Hongwei Li • \\ Chenghong Peng
}

Received: 17 December 2012 / Accepted: 5 March 2013 /Published online: 19 July 2013

(C) 2013 The Author(s). This article is published with open access at Springerlink.com

\begin{abstract}
Background Cholangiocarcinoma (CCA) is becoming a common fatal hepatic tumor. Early detection of CCA is hampered by the absence of a sufficiently accurate and noninvasive diagnostic test. Proteomic analysis would be a powerful tool to identify potential biomarkers of this cancer.

Aims This study aims to identify new protein markers that are specific for CCA using proteomic approaches and to evaluate the performance of S100 calcium-binding protein A9 (S100A9) and chaperonin-containing TCR1, subunit 3 (CCT $\gamma$ ) as diagnostic markers for screening test of CCA.

Methods Two-dimensional differential gel electrophoresis (2-D DIGE) coupled with matrix-assisted laser desorption/ionization time-of-flight (MALDI-TOF) mass spectrometry were used to analyze and screen biomarker candidates in the proteomes of five human CCA samples and five healthy control samples. Subsequently, two potential biomarkers, S100A9 and $\mathrm{CCT} \gamma$, were chosen for validation and analysis by immunohistochemical methods using CCA tissue microarrays.

Results Twenty protein spots were significantly elevated and five protein spots were downregulated in all patients $(p<0.05)$. The positive rate was significantly higher in patients with CCA $(48 \pm 35 \%)$ compared with the normal liver control group ( $5 \pm$ $10 \%, p<0.001)$, the hepatocellular carcinoma group $(15 \pm 20 \%, p<0.001)$, and the cirrhosis group $(12 \pm 16 \%, p<0.001)$. A greater proportion of patients with CCA were positive for CCT $\gamma(72 \pm 18 \%)$ compared with the normal liver control group (43 \pm $22 \%, p<0.001)$, the hepatocellular carcinoma group $(45 \pm 20 \%, p<0.001)$, and the cirrhosis group $(39 \pm 25 \%, p<0.001)$.

Conclusions Combined comparative proteomic analysis using 2-D DIGE and MALDI-TOF is an effective method for identifying differentially expressed proteins in CCA tissues. The expression of S100A9 and CCT $\gamma$ showed promise as novel diagnostic markers for CCA.
\end{abstract}

Keywords Liver cancer · Cholangiocarcinoma $\cdot 2$-D DIGE · Proteomics $\cdot$ S100 A9 $\cdot$ CCT $\gamma$

Y. Shi $\cdot$ X. Deng $(\triangle) \cdot$ Q. Zhan $\cdot$ B. Shen $\cdot$ Z. Zhu $\cdot$ H. Chen $\cdot$

$\mathrm{H}$. Li $\cdot$ C. Peng $(\triangle)$

Department of Surgery, Ruijin Hospital, Shanghai Jiao Tong

University School of Medicine, 197 Ruijin Er RD,

Shanghai 200025, People's Republic of China

e-mail: submit_dxx@sohu.co

e-mail: chhpeng@188.net

X. Jin

Department of Pathology, Ruijin Hospital, School of Medicine,

Shanghai Jiao Tong University, Shanghai 200025, China

\section{Introduction}

Cholangiocarcinoma (CCA) is a malignant tumor that originates from the bile duct epithelium. Among primary liver tumors, CCA accounts for an estimated $15 \%$ of primary liver cancers worldwide ${ }^{1}$ and is becoming a common type of fatal hepatic tumor. CCA is responsible for more than $60 \%$ of liver tumors in parts of Southeast Asia, especially in northeastern Thailand. Tumor stage, resectability, and survival are all closely correlated in patients with bile duct carcinoma, suggesting that early detection strategies may improve the prognosis of patients with this disease. ${ }^{2,3}$ However, early detection of CCA is hampered by the absence of a sufficiently accurate and noninvasive diagnostic 
test. ${ }^{4}$ Carcinoembryonic antigen (CEA) and carbohydrate antigen 19-9 (CA19-9) are used as markers for early-stage biliary carcinoma in patients. CEA is nonspecific and can be elevated in the setting of other gastrointestinal or gynecologic malignancies or other bile duct pathologies, such as cholangitis and hepatolithiasis. ${ }^{5}$ The sensitivity and specificity of CA19-9 are 53-89 and 80.5-86.0\%, respectively., Several biliary markers, including MMP-9, MMP-7, Mac-2binding protein, and the transcriptional repressor Slug, have shown promise in the diagnosis of CCA. ${ }^{7-10}$

In recent years, proteomic analysis has been considered a powerful tool for investigating cancer mechanisms. ${ }^{11}$ Combined comparative proteomic analysis by twodimensional differential gel electrophoresis (2-D DIGE) and matrix-assisted laser desorption/ionization time-offlight mass spectrometry (MALDI-TOF-MS) is an effective method for identifying differentially expressed proteins. ${ }^{12,13}$

In this study, we identified several proteins that were elevated or downregulated in CCA compared with normal liver using a 2-D DIGE approach. Some of these proteins may be biomarkers for early diagnosis, prognosis, or monitoring in the therapy of CCA. Two of these proteins, chaperonin-containing TCP1 subunit $3(\gamma)(C C T \gamma)$ and S100 calcium-binding protein A9 (S100A9), were measured using tissue microarrays to evaluate their performance as diagnostic markers for CCA.

\section{Materials and Methods}

\section{Patients and Samples}

The study design was approved by the independent ethics committee of Ruijin Hospital, and the procedure was described in detail to all patients before admission and informed consent was obtained. The human liver tissue samples used for 2D-DIGE were obtained from seven surgical patients (mean age 62 years) in Ruijin Hospital who had a clinical diagnosis of CCA between January 2008 and June 2009. These patients included four intrahepatic cholangiocarcinoma cases and three hilar cholangiocarcinoma cases. Two cases that were hepatoma by pathologic diagnosis were excluded from this study. Human liver tissue samples from five patients (mean age 57 years) with a pathologic diagnosis of cholangitis between January 2009 and June 2009 were used as controls. The specimens were quickly removed during surgery and stored immediately in liquid nitrogen until later experiments.

For immunohistochemistry, formalin-fixed, paraffinembedded biliary carcinoma tissue samples and control samples were obtained from the surgical pathology archives of the Department of Pathology at the Ruijin Hospital of Shanghai Jiao Tong University. Forty CCA patients (26 men and 14 women) aged $41-80$ years (mean, $62.5 \pm 11$ years) underwent liver resection at the Ruijin Hospital of Shanghai
Jiao Tong University (China) from 2007 to 2009. Tissue samples were collected from patients with intrahepatic biliary cystadenocarcinoma $(n=5)$, patients with intrahepatic cholangiocarcinoma $(n=17)$, patients with hilar cholangiocarcinoma $(n=14)$, and patients with hepatobiliary cystadenoma $(n=4)$, and 30 patients with hepatocellular carcinoma, 30 patients with cirrhosis, and 10 normal liver tissues were collected as control group.

\section{2-D DIGE and Image Analysis}

This study was followed the standard methods of twodimensional differential gel electrophoresis proteomics technology. ${ }^{14}$ These tissues were cut into $3 \mathrm{~mm}^{3}$ pieces and digested with $1 \mathrm{ml}$ DIGE lysis buffer. The digested samples were homogenized with Dounce Tissue Grinders, vortexed, sonicated at $4{ }^{\circ} \mathrm{C}$, and placed on ice. Extracts were centrifuged at $14,000 \times g$ for $1 \mathrm{~h}$, and the supernatants were collected. A pooled internal standard to control for gel-to-gel variation was prepared by mixing an equal amount of all tumoral and non-tumoral samples that had been diluted to $5 \mu \mathrm{g} / \mu \mathrm{l}$. A total of $50 \mu \mathrm{g}$ of tumoral and non-tumoral protein extracts with a $\mathrm{pH}$ of 8.9-9.0 were minimally labeled with cyanine fluorochrome 3 (Сy3) or Cy5, and the pooled internal standard was labeled with Cy2.

Three Cy-labeled protein samples (tumoral, non-tumoral, and internal standard) were mixed. The mixtures were added to an equal volume of sample buffer. All of the samples were mixed, and the volume was adjusted to $250 \mu \mathrm{l}$ with rehydration buffer. The first dimension was performed on an Ettan IPGphor Isoelectric Focusing System (GE Amersham) using $13 \mathrm{~cm}$ immobilized $\mathrm{pH}$ gradient strips with a $\mathrm{pH}$ of 3-10. After isoelectric focusing, the gel strips were then equilibrated in equilibration buffer. The equilibrated strips were loaded on the top of a $12.5 \%$ sodium dodecyl sulfate-polyacrylamide gel electrophoresis gel. Electrophoresis was performed using a Hoefer SE 600 unit (GE, Amersham Biosciences). After 2DDIGE, the gels were scanned with an UMax PowerLook 2100XL (GE, Amersham Biosciences). The excitation and emission wavelengths for Cy2, Сy3, and Cy5 are 488/520, $532 / 580$, and $633 / 670 \mathrm{~nm}$, respectively.

\section{MS}

After scanning, the gels were stained using the Coomassie Blue Staining method. The protein spots were cut from gels destained by washing in MilliQ distilled water. After trypsin digestion and evaporation, the MALDI-TOF/MALDI-TOFTOF analyses (Bruker Daltonics, Bremen Germany) were performed to acquire mass spectra for all the peptides. Tryptic digests were prepared in an AnchorChip sample plate (Bruker Daltonics) according to the manufacturer's protocol. MS data were acquired with an $\mathrm{N}_{2}$ laser at a sampling rate of $25 \mathrm{~Hz}$. The tryptic peptide mass maps were transferred with the MS 
BioToolsTM program (Bruker Daltonics) using MASCOT software (Matrix Science). Then, the National Center for Biotechnology Information (NCBI) non-redundant database was searched with human as the taxonomy.

Proteins were unambiguously identified through their peptide mass fingerprinting (PMF) and MS/MS ion search using MASCOT to interrogate the NCBI Inr 20090820 (9511482 sequences; 3251602805 residues). The ion score is $-10 \times \log (P)$, where $P$ is the probability that the observed match is a random event. Individual ions scores greater than a certain number indicate identity or extensive homology ( $p$ $<0.05$ ). The protein scores are derived from ion scores as a non-probabilistic basis for ranking protein hits. Protein scores $>66$ are considered statistically significant $(p<0.05)$ under the parameters described previously.

\section{S100A9 and CCT $\gamma$ Tissue Microarrays}

Tissue microarrays were constructed as described previously. ${ }^{15}$ For the immunohistochemical analysis, the tissue microarrays were deparaffinized in xylene and graded ethanols, washed with three times with PBS, and boiled in citrate buffer (antigen retrieval solution; DAKO, Carpinteria, CA). Endogenous peroxidases were blocked by incubation and incubation overnight with mouse antihuman monoclonal antibody. After washing, biotin and a streptavidin-horseradish peroxidase conjugate were applied. The peroxidase reaction was visualized by applying diaminobenzidine tetrahydrochloride (DAB) containing hydrogen peroxide (Liquid DAB Substrate Chromogen System; DAKO); sections were subsequently developed by washing by water, counterstained with hematoxylin, dehydrated, and mounted.

Immunohistochemical staining intensity and area were assessed by two observers and were expressed as the staining intensity of positive carcinoma. Staining intensity was scored as negative, $* 1,1,2$, and 3 , which represent negative, weakly positive, mildly positive, moderately positive, or strongly positive. The staining area was scored as negative (without staining), *1 (weak yellow staining), 1 (light brown staining), 2 (yellow or brown staining), or 3 (dark yellow or dark brown staining). The positive rate of the microarrays was calculated as the percentage of positively stained carcinoma cells among all cells.

\section{Statistical Analysis}

All statistical analyses were performed using SPSS 13.0 software (SPSS, Chicago, USA). After 2D-DIGE, three images corresponding to three samples labeled with three different $\mathrm{Cy}$ dyes were generated in one gel. A $t$ test was performed for every matched spot set, comparing the average and SD of protein abundance for a given spot. Pixel values from images of a small area of fluorescent-stained gels were converted into
3-D representations to illustrate the differential quantification between the two groups.

Differences between S100A9 and CCT $\gamma$ expression in tumoral tissues and control group were analyzed using a paired Student's $t$ test. An receiver operating characteristic (ROC) curve was generated by plotting the sensitivity against 1-specificity, and the area under the curve with $95 \%$ confidence intervals $(\mathrm{CI})$ was calculated. The optimal cutoff points for S100A9 and CCT $\gamma$ were selected based on the ROC curve analysis. The sensitivity, specificity, positive predictive value, and negative predictive value were calculated using a $2 \times 2$ table of the collected data.

\section{Results}

Analysis of Differentially Expressed Proteins

Tissue samples collected from five patients with CCA and five normal controls were run on 2-D DIGE to elucidate changes in protein expression between tumors and normal controls (Fig. 1). The average ratio and $p$ for a given spot between patients and normal controls was calculated, and these values are shown in Table 1. Using the biological variation analysis module of the DeCyder software, 25 differentially expressed proteins were selected. Twenty proteins were significantly elevated in all patient groups (with average ratios from -1.60 to -4.47 ), while five proteins were significantly downregulated in patients (with ratios

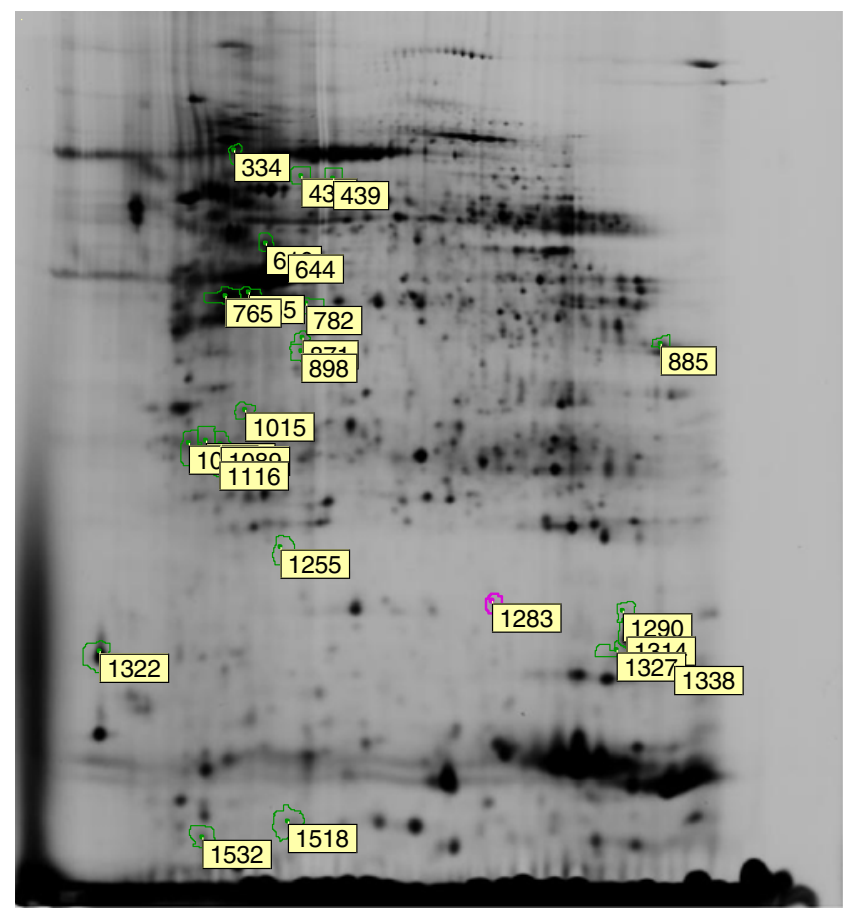

Fig. 1 Representative 2D gel images indicating the differential spots 
Table 1 Differentially expressed proteins, as determined by Student's $t$ test between the normal control and tumor groups

\begin{tabular}{|c|c|c|c|}
\hline Pos. & Protein spots & $p$ value & Average ratio \\
\hline 1 & 765 & 0.0054 & -4.47 \\
\hline 2 & 1532 & 0.0060 & -4.46 \\
\hline 3 & 755 & 0.0012 & -3.66 \\
\hline 4 & 885 & 0.0056 & -3.55 \\
\hline 5 & 1314 & 0.0023 & -3.33 \\
\hline 6 & 1283 & 0.0095 & -3.27 \\
\hline 7 & 1518 & 0.0020 & -3.21 \\
\hline 8 & 1015 & 0.00069 & -2.65 \\
\hline 9 & 1089 & 0.0042 & -2.62 \\
\hline 10 & 1290 & 0.0091 & -2.47 \\
\hline 11 & 644 & 0.0094 & -2.46 \\
\hline 12 & 1327 & 0.0043 & -2.31 \\
\hline 13 & 1116 & 0.0042 & -1.97 \\
\hline 14 & 1338 & 0.0097 & -1.92 \\
\hline 15 & 1322 & 0.0047 & -1.89 \\
\hline 16 & 1083 & 0.0013 & -1.82 \\
\hline 17 & 1082 & 0.0093 & -1.78 \\
\hline 18 & 871 & 0.0081 & -1.69 \\
\hline 19 & 898 & 0.0070 & -1.69 \\
\hline 20 & 610 & 0.0014 & -1.60 \\
\hline 21 & 439 & 0.0030 & 1.35 \\
\hline 22 & 1255 & 0.0033 & 1.49 \\
\hline 23 & 431 & 0.0020 & 1.83 \\
\hline 24 & 334 & 0.0056 & 1.90 \\
\hline 25 & 782 & 0.0085 & 2.16 \\
\hline
\end{tabular}

from 1.35 to 2.16), and the statistical variance of the tumor versus the normal spot volume ratios was within the $95 \%$ confidence level (Student's $t$ test; $p<0.05$ ) (Table 1).

\section{Identification of Differentially Expressed Proteins}

Sixteen protein spots were selected for tryptic digestion and MALDI-TOF or MALDI-TOF/TOF analysis. Fortunately, 13 out of 16 proteins were unambiguously identified (Fig. 2 is the Mascot score schematic diagram of two of all the identified proteins). Three proteins $(644,898$, and 1327) were identified by PMF. The other ten proteins were searched by MS/MS ion search. Eleven protein spots were upregulated and two protein spots were downregulated in patients (Table 2).

\section{S100A9 and CCT $\gamma$ Immunohistochemistry}

S100A9 and CCT $\gamma$ expression was measured by immunohistochemistry in tissue samples from 40 patients with CCA, 30 patients with hepatocellular carcinoma, 30 patients with cirrhosis, and 10 normal liver tissues. S100A9 was detected
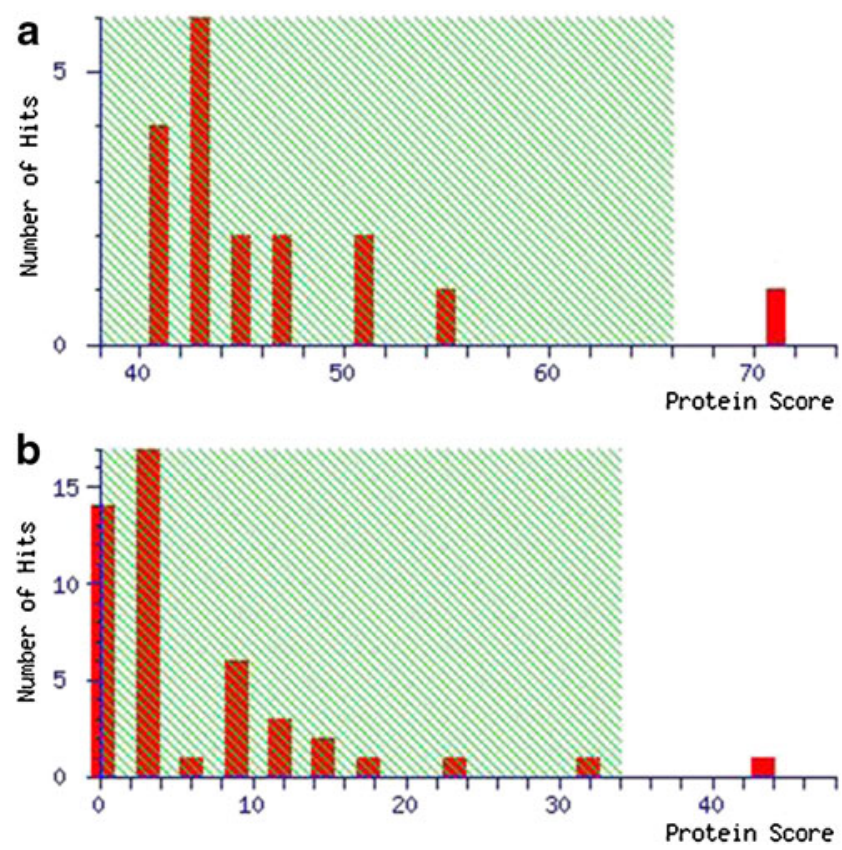

Fig. 2 Mascot score schematic diagram: $x$-axis as Mascot score (protein score), the $y$-axis is the number of matching. Score that exceeds the shaded area obtained positive identification $(p<0.05)$. a The matching and sequence coverage of protein no. 644 and protein ID gi|55960506 in database. $\mathbf{b}$ The matching and sequence coverage of protein no. 1518 and protein ID gi|4506773 in database

in 37 of 40 tumor tissue samples $(92.5 \%)$. Staining scores of *1-1 (weak-mildly positive), 1 (mildly positive), $1-2$ (mild-moderately positive), and 2 (moderately positive) were found in 2, 23, 9, and 3 tumor tissue samples, respectively. Positive S100A9 staining ( $>5 \%$ of carcinoma cells stained) was observed in the cytoplasm of carcinoma cells (Fig. 3a). S100A9 was expressed only in three out of ten normal tissue samples (Fig. 3b), 14 out of 30 hepatocellular carcinoma samples (Fig. 3c), and 12 out of 30 cirrhosis samples (Fig. 3d). The positive rate was significantly higher in patients with CCA $(48 \pm 35 \%)$ compared to the normal liver control group $(5 \pm 10 \%, p<0.001)$, the hepatocellular carcinoma group $(15 \pm 20 \%, p<0.001)$, and the cirrhosis group $(12 \pm 16 \%, p<0.001)$.

CCT $\gamma$ was also detected in 37 of 40 tumor tissue samples ( $92.5 \%)$. Staining scores of $* 1-1$ (weak-mildly positive), 1 (mildly positive), 1-2 (mild-moderately positive), and 2 (moderately positive) were found in 3, 14, 14, and 6 tumor tissue samples, respectively. Positive CCT $\gamma$ staining ( $>10 \%$ of carcinoma cells stained) was observed in the cytoplasm of carcinoma cells (Fig. 4a). CCT $\gamma$ had low levels of expression in normal tissue samples (Fig. 4b), hepatocellular carcinoma tissue samples (Fig. 4c), and cirrhosis samples (Fig. 4d). Staining scores of 1 and 1-2 were found in eight and two normal tissue samples, respectively, and the positive rate was significantly higher in patients with CCA $(72 \pm 18 \%)$ compared to the normal liver control group (43 \pm 
Table 2 Differentially expressed proteins identified by MALDI-TOF after 2-D DIGE

\begin{tabular}{|c|c|c|c|c|c|c|c|c|}
\hline $\begin{array}{l}\text { Spot } \\
\text { no. }\end{array}$ & Protein ID & Name & $\mathrm{Mr}$ & PI & $\begin{array}{l}\text { Sequence } \\
\text { coverage } \\
(\%)\end{array}$ & Score & $\begin{array}{l}\text { Peptide } \\
\text { matches }\end{array}$ & Matched sequence \\
\hline 334 & gi|28592 & Serum albumin (Homo sapiens) & 71316 & 6.05 & 3 & 65 & 2 & $\begin{array}{l}\text { K.YLYEIAR.R } \\
\text { K.KVPQVSTPTLVEVSR.N }\end{array}$ \\
\hline 610 & gi|3420181 & WDR1 protein (Homo sapiens) & 58593 & 6.41 & 5 & 38 & 2 & $\begin{array}{l}\text { K.VFASLPQVER.G } \\
\text { R.LATGSDDNCAAFFEGPPFK.F }\end{array}$ \\
\hline 644 & gi|55960506 & $\begin{array}{l}\text { Chaperonin-containing TCP1, } \\
\text { subunit } 3(\gamma) \text { (Homo sapiens) }\end{array}$ & 58505 & 6.46 & 22 & 71 & 9 & $\begin{array}{l}\text { R.TQDEEVGDGTTTVVISAYRK.A } \\
\text { R.VEKIPGGIIEDSCVLR.G } \\
\text { K.IPGGIIEDSCVLR.G } \\
\text { K.GISDLAQHYLMR.A } \\
\text { R.IVSRPEELREDDVGTGAGLLEIK.K } \\
\text { K.AMTGVEQWPYR.A } \\
\text { R.AVAQALEVIPR.T } \\
\text { R.TLIQNCGASTIR.L } \\
\text { K.TAVETAVLLLR.I }\end{array}$ \\
\hline 782 & gi|4501901 & Aminoacylase 1 (Homo sapiens) & 46084 & 5.77 & 5 & 39 & 2 & $\begin{array}{l}\text { K.GPEEEHPSVTLFR.Q } \\
\text { K.VVNSILAFR.E }\end{array}$ \\
\hline 871 & gi|5031777 & $\begin{array}{l}\text { Isocitrate dehydrogenase } 3 \text { (NAD+) } \\
\text { alpha precursor (Homo sapiens) }\end{array}$ & 40022 & 6.47 & 8 & 108 & 3 & $\begin{array}{l}\text { K.APIQWEER.N } \\
\text { K.TPYTDVNIVTIR.E } \\
\text { R.IAEFAFEYAR.N }\end{array}$ \\
\hline 885 & gi|1575000 & 2,4-Dienoyl-CoA reductase & 36096 & 9.50 & 6 & 45 & 1 & K.VAGHPNIVINNAAGNFISPTER.L \\
\hline 898 & gi|62896849 & $\begin{array}{l}N \text {-acetylglucosamine kinase } \\
\text { variant (Homo sapiens) }\end{array}$ & 37697 & 5.81 & 31 & 120 & 11 & $\begin{array}{l}\text { R.KAGVDPLVPLR.S } \\
\text { K.AGVDPLVPLR.S } \\
\text { R.SLGLSLSGGDQEDAGR.I } \\
\text { K.QAMFHYFQVPDR.L } \\
\text { R.LGILTHLYR.D } \\
\text { R.FAGFCRK.I } \\
\text { R.KIAEGAQQGDPLSR.Y } \\
\text { K.IAEGAQQGDPLSR.Y } \\
\text { K.EGFLLALTQGR.E } \\
\text { R.EIQAQNFFSSFTLMK.L } \\
\text { R.HSSALGGASLGAR.H }\end{array}$ \\
\hline 1082 & gi|4757768 & $\begin{array}{l}\text { Rho GDP dissociation inhibitor } \\
\text { (GDI) alpha (Homo sapiens) }\end{array}$ & 23250 & 5.02 & 17 & 119 & 3 & $\begin{array}{l}\text { K.YIQHTYR.K } \\
\text { K.IDKTDYMVGSYGPR.A } \\
\text { R.AEEYEFLTPVEEAPK.G }\end{array}$ \\
\hline 1089 & gi|539605 & $\begin{array}{l}\text { GTP-binding protein G25K } \\
\text { - human (fragments) }\end{array}$ & 6419 & 6.34 & 23 & 42 & 1 & R.IDKTDYMVGSYGPR.- \\
\hline 1314 & gi|1421609 & $\begin{array}{l}\text { Chain A, X-ray structure of Nm23 } \\
\text { human nucleoside diphosphate } \\
\text { kinase B complexed with GDP at } \\
2 \AA \text { resolution }\end{array}$ & 17290 & 8.55 & 20 & 45 & 3 & $\begin{array}{l}\text { R.TFIAIKPDGVQR.G } \\
\text { K.DRPFFPGLVK.Y } \\
\text { R.GDFCIQVGR.N }\end{array}$ \\
\hline 1322 & gi|226449 & Cytochrome b5 & 15218 & 4.82 & 49 & 242 & 5 & $\begin{array}{l}\text { K.YYTLEEIQK.H } \\
\text { K.STWLILHHK.V } \\
\text { K.FLEEHPGGEEVLR.E } \\
\text { R.EQAGGDATENFEDVGHSTDAR.E } \\
\text { K.TFIIGELHPDDRPK.L }\end{array}$ \\
\hline 1327 & $\begin{array}{l}\text { Mixture 1, } \\
\text { gi|5453541 + } \\
\text { gi| } 1421609\end{array}$ & $\begin{array}{l}\text { Anterior gradient } 2 \text { homolog (Homo } \\
\text { sapiens) chain A, X-ray structure } \\
\text { of Nm23 human nucleoside } \\
\text { diphosphate }\end{array}$ & 20024 & 9.03 & 26 & 68 & 5 & $\begin{array}{l}\text { K.LPQTLSR.G } \\
\text { K.HLSPDGQYVPR.I } \\
\text { R.IMFVDPSLTVR.A } \\
\text { R.LYAYEPADTALLLDNMK.K }\end{array}$ \\
\hline
\end{tabular}


Table 2 (continued)

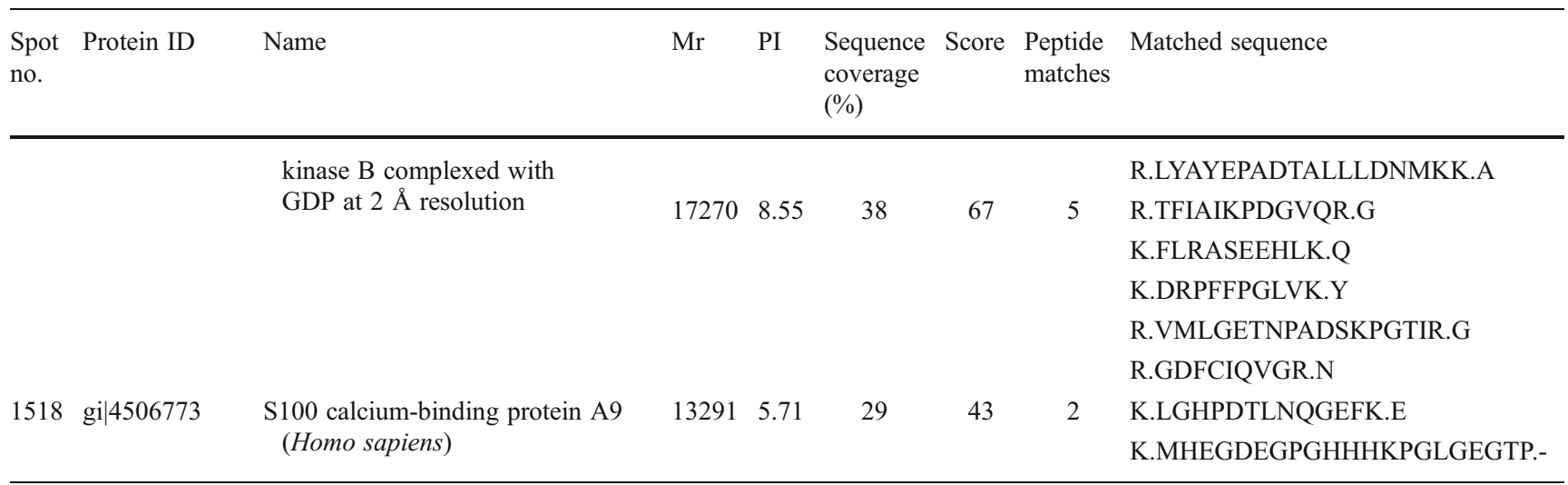

$22 \%, p<0.001)$, the hepatocellular carcinoma group (45 $20 \%, p<0.001)$, and the cirrhosis group ( $39 \pm 25 \%, p<0.001)$.

An ROC curve analysis (Fig. 5) was used to calculate an area under the curve of $0.894(95 \% \mathrm{CI}=0.825-0.962)$ for S100A9 and 0.860 (95 \% CI=0.779-0.942) for CCT $\gamma$. When the cutoff value of S100A9 was set at $4 \%$, the sensitivity and specificity for the diagnosis of CCA were 92.6 and $75 \%$, respectively. When the cutoff value for CCT $\gamma$ was set at $62.5 \%$, the sensitivity and specificity for the diagnosis of CCA were 80.8 and $77.8 \%$, respectively.

\section{Discussion}

Detecting new biomarkers for early-stage biliary carcinoma in patients may improve the prognosis of patients with CCA. Due to the low incidence of CCA, a retrospective study based on liver tissue is necessary for further research.
In this study, the analysis of the 2-D DIGE gels showed a large number of differentially expressed proteins in CCA. Some of these proteins are predicted to play roles in tumorigenesis or tumor growth ${ }^{16-18}$ and may be potential biomarkers in early screening test. S100A9 and CCT $\gamma$ were detected by immunohistochemistry in 50 tissue samples, and the expression was significantly elevated in patients with a diagnosis of CCA when compared to control groups. It is shown that the sensitivity and specificity of S100A9 were 92.6 and $75 \%$ when using a cutoff value of $4 \%$. The sensitivity and the specificity of CCT $\gamma$, however, were 80.8 and $77.8 \%$, respectively, when using a cutoff value of $4 \%$. The diagnostic accuracy of S100A9 and CCT $\gamma$ as biomarkers compared favorably with the performance of other protein markers for patients with biliary tract carcinoma (specifically, CEA, CA125, CA19-9, and fibronectin), which have reported sensitivities of $58-78 \%$ and specificities of $33-84 \%$. This study demonstrated that there is a significant difference in S100A9
Fig. 3 a Immunoperoxidase stains of a CCA case that is positive for S100A9, $\times 400$ (the arrow points out a positive cell). b Immunoperoxidase stains of a non-CCA case that is negative for S100A9, $\times 400$. c Immunoperoxidase stain of a case of hepatocellular carcinoma that is negative for S100A9, $\times 400$. d

Immunoperoxidase stain of case of cirrhosis that is negative for $\mathrm{S} 100 \mathrm{~A} 9, \times 400$
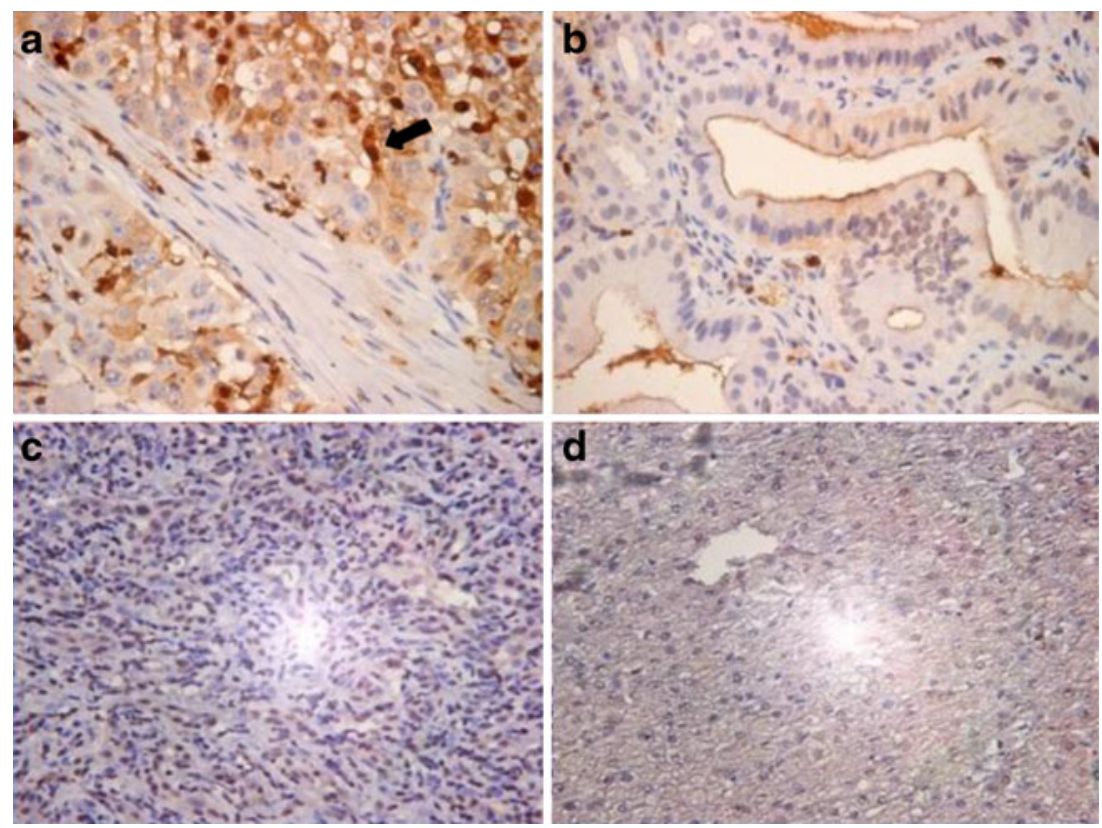
Fig. 4 a Immunoperoxidase stains of a CCA case that is positive for $\mathrm{CCT} \gamma, \times 200$ (the arrow points out a positive cell). b Immunoperoxidase stains of a non-CCA case that is negative for $\mathrm{CCT} \gamma, \times 200$. c Immunoperoxidase stain of a case of hepatocellular carcinoma that is negative for $\mathrm{CCT} \gamma, \times 400$. d

Immunoperoxidase stain of case of cirrhosis that is negative for $\mathrm{CCT} \gamma, \times 400$
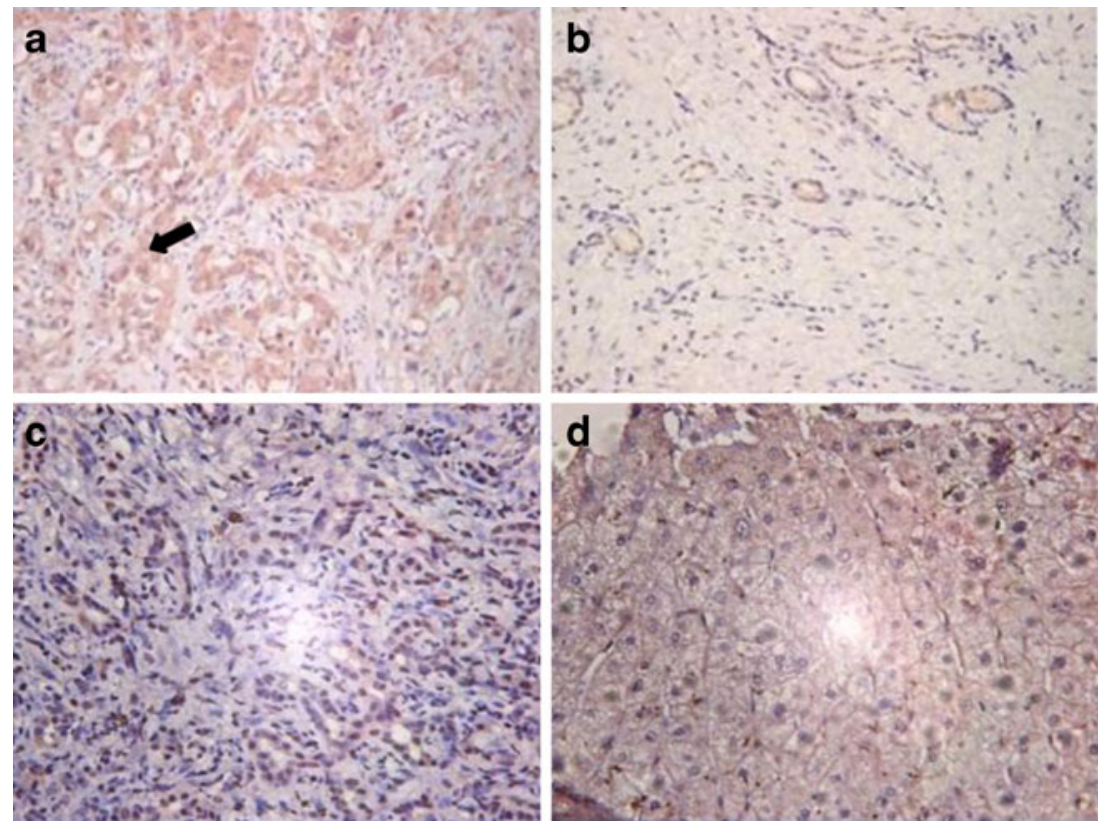

and CCT $\gamma$ expression between CCA patients and control patients.

The S100 family of proteins includes a group of small acidic proteins with common EF-hand calcium-binding motifs. S100 proteins regulate a variety of cellular processes, including cellular proliferation, differentiation, motility, secretion, membrane permeability, protein synthesis, and extracellular signal transduction. S100A8 and S100A9 are two members of the S100 protein family. S100A8 and S100A9 are key effectors/amplifiers of inflammation, with a wide range of activities, including cytokine induction. Subsequently, it has emerged as an important proinflammatory mediator in acute and chronic inflammation. More recently, increased S100A8 and S100A9 levels were also detected in various human cancers, such as skin, colorectal, breast, prostate, and lung. ${ }^{19-22}$ Numerous studies demonstrate that the serum level of S100A9 is significantly elevated in many types of cancers, including breast cancer, esophageal cancer, and lung cancer. ${ }^{23,24} \mathrm{~A}$ recent report suggested the calcium-binding protein S100P is upregulated in CCA. S100P was frequently expressed in the CCA tissues but not in the normal bile duct. The brushing cytology samples from the CCA cases revealed increased expression of S100P compared with the benign biliary strictures. The relative expression level of S100P could identify CCA at a higher sensitivity than classical cytology, and the combination of the S100P expression level and cytology yielded a sensitivity of $90.0 \%$, with a specificity of $92.0 \%{ }^{25}$

The chaperonin-containing t-complex polypeptide 1 (CCT), also called TRiC or c-cpn, mediates protein folding in the cytosol. CCT is a member of the chaperonin family, which includes mitochondrial Hsp60, bacterial GroEL, plastid Rubisco subunit-binding protein, and archaea group II chaperonins. $^{26,27}$ CCT shows a double-torus-like structure with eightfold rotational symmetry, and the complete complex is assembled from 16 subunits. The chaperonins are key molecular complexes that are essential in protein folding to produce stable and functionally competent protein conformations. ${ }^{28,29}$ One member of the chaperonin group of proteins is TCP1
Fig. 5 Receiver operating characteristic (ROC) curve analyses of S100A9 and CCT $\gamma$ for the diagnosis of cholangiocarcinoma. The diagnostic accuracy of each biomarker, in terms of its sensitivity and specificity, were presented by ROC curve analysis. $\mathbf{a}$ and $\mathbf{b}$ correspond to S100A9 and CCT $\gamma$. Only the area under the curve (AUC) of the ROC is significantly higher than a chance value $(0.5)$

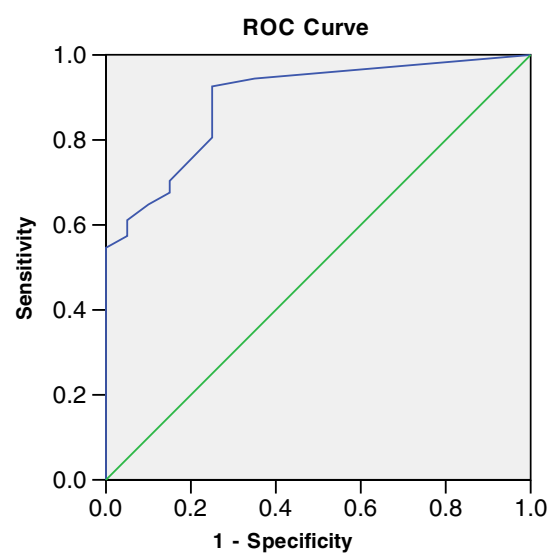

Diagonal segments are produced by ties.

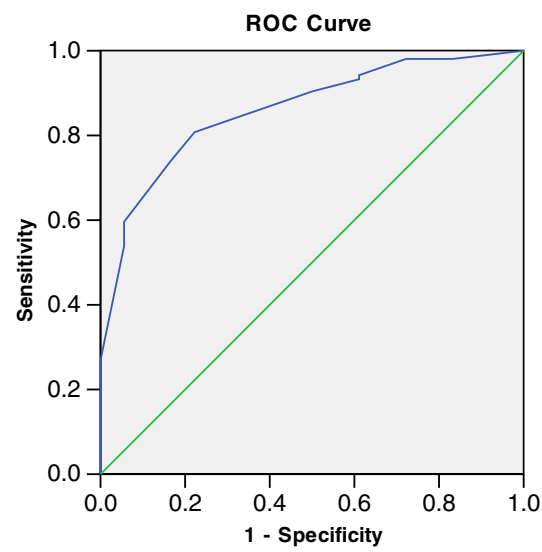

Diagonal segments are produced by ties. 
(chaperonin-containing t-complex polypeptide 1 or $\mathrm{CCT}$ ). Increased expression of cytosolic chaperonin CCT in human hepatocellular and colonic carcinoma has been reported. ${ }^{18}$

Though proteomic approaches in CCA are currently at an early stage, further research could be conducted to early diagnose or evaluate the prognosis. It is believed that varied protein expression of different tumor location, size, lymphatic involvement, degree of fibrosis, specific histology, etc. would also be found in further research based on this study. Further experiments are being conducted to contrast the expression of S100A9 and CCT $\gamma$ between CCA and HCC patients based on bile or serum, which could be helpful in early diagnosis of CCA.

In conclusion, two potential biomarkers, S100A9 and $\mathrm{CCT} \gamma$, were found by proteomic screening and confirmed by immunohistochemistry. Our research suggests that these two proteins have the potential to be used as new tumor markers for early detection of CCA. Further studies involving a larger patient population and serum S100A9 and $\mathrm{CCT} \gamma$ levels are needed to provide more information regarding the diagnostic accuracy of S100A9 and CCT $\gamma$.

Acknowledgments This study was supported by Shanghai Science and Technology Commission Project grant for 2010 (10411955600).

Open Access This article is distributed under the terms of the Creative Commons Attribution License which permits any use, distribution, and reproduction in any medium, provided the original author(s) and the source are credited.

\section{References}

1. Shaib YH, El-Serag HB, Davila JA, Morgan R, McGlynn KA. Risk factors of intrahepatic cholangiocarcinoma in the United States: a case-control study. Gastroenterology 2005; 128: 620-626

2. Khan SA, Davidson BR, Goldin R, Pereira SP, Rosenberg WM, Taylor-Robinson SD, Thillainayagam AV, Thomas HC, Thursz MR, Wasan H; British Society of Gastroenterology. Guidelines for the diagnosis and treatment of cholangiocarcinoma: consensus document. Gut 2002; 51 Suppl 6: VI1-VI9

3. Yoon JH, Gores GJ. Diagnosis, staging, and treatment of cholangiocarcinoma. Curr Treat Options Gastroenterol 2003; 6: 105112

4. Gores GJ. Early detection and treatment of cholangiocarcinoma. Liver Transplant 2000; 6: S30 -S34

5. Van Beers BE. Diagnosis of cholangiocarcinoma. HPB (Oxford) 2008; 10(2): 87-93

6. Patel AH, Harnois DM, Klee GG, LaRusso NF, Gores GJ. The utility of CA 19-9 in the diagnoses of cholangiocarcinoma in patients without primary sclerosing cholangitis. Am J Gastroenterol 2000; 95: 204-207

7. Leelawat K, Narong S, Wannaprasert J, Ratanashu-ek T. Prospective study of MMP7 serum levels in the diagnosis of cholangiocarcinoma. World J Gastroenterol 2010; 16(37): 4697-4703

8. Zhang KJ, Zhang BY, Zhang KP, Tang LM, Liu SS, Zhu DM, Zhang DL. Clinicopathologic significance of slug expression in human intrahepatic cholangiocarcinoma. World J Gastroenterol 2010; 16(20): 2554-2557.

9. Leelawat K, Sakchinabut S, Narong S, Wannaprasert J. Detection of serum MMP-7 and MMP-9 in cholangiocarcinoma patients: evaluation of diagnostic accuracy. BMC Gastroenterol 2009; 9: 30

10. Koopmann J, Thuluvath PJ, Zahurak ML, Kristiansen TZ, Pandey A, Schulick R, Argani P, Hidalgo M, Iacobelli S, Goggins M, Maitra A. Mac-2-binding protein is a diagnostic marker for biliary tract carcinoma. Cancer 2004; 101(7): 1609-1615.

11. He YD. Genomic approach to biomarker identification and its recent applications. Cancer Biomark 2006; 2: 103-133

12. Wittmann-Liebold B, Graack HR, Pohl T. Two dimensional gel electrophoresis as tool for proteomics studies in combination with protein identification by mass spectrometry. Proteomics 2006; 6: 4688-4703

13. Ma Y, Peng J, Huang L, Liu W, Zhang P, Qin H. Searching for serum tumor markers for colorectal cancer using a 2-D DIGE approach. Electrophoresis 2009; 30(15): 2591-2599

14. Robert T, Joanne Sh, Brian M, Rachel R, Steve R, Janice Y, Francois P, Edward H, Lan C, Matthew Davison. Validation and development of fluorescence two-dimensional differential gel electrophoresis proteomics technology. PROTEOMICS 2001; 3: 377-396

15. Manley S, Mucci NR, De Marzo AM, Rubin MA. Relational database structure to manage high-density tissue microarray data and images for pathology studies focusing on clinical outcome: the prostate Specialized Program of Research Excellence model. Am J Pathol 2001; 1599(3): 837-843

16. Gebhardt C, Németh J, Angel P, Hess J. S100A8 and S100A9 in inflammation and cancer. Biochem Pharmacol 2006; 72(11): 1622-1631

17. Lai CC, You JF, Yeh CY, Chen JS, Tang R, Wang JY, Chin CC. Low preoperative serum albumin in colon cancer: a risk factor for poor outcome. Int J Colorectal Dis 2011; 26(4): 473-481.

18. Coghlin C, Carpenter B, Dundas SR, Lawrie LC, Telfer C, Murray GI. Characterization and over-expression of chaperonin t-complex proteins in colorectal cancer. J Pathol 2006; 210(3): 351-357

19. Hermani A, Hess J, De Servi B, Medunjanin S, Grobholz R, Trojan L, Angel P, Mayer D. Calcium-binding proteins S100A8 and S100A9 as novel diagnostic markers in human prostate cancer. Clin Cancer Res 2005; 11: 5146-5152

20. Ichikawa M, Williams R, Wang L, Vogl T, Srikrishna G. S100A8/ A9 activate key genes and signaling pathways in colon tumor progression. Mol Cancer Res. 2011; 9(2): 133-148

21. McKiernan E, McDermott EW, Evoy D, Crown J, Duffy MJ. The role of S100 genes in breast cancer progression. Tumour Biol 2011; 32(3): 441-450

22. Su YJ, Xu F, Yu JP, Yue DS, Ren XB, Wang CL. Up-regulation of the expression of S100A8 and S100A9 in lung adenocarcinoma and its correlation with inflammation and other clinical features. Chinese Medical Journal 2010; 123(16): 2215-2220

23. Jang L, He L, Fountoulakis M. Comparison of protein precipitation methods for sample preparation prior to proteomic analysis. J Chromatogr A 2004; 1023: 317-320

24. Park MR, Wang EH, Jin DC, Cha JH, Lee KH, Yang CW, Kang CS, Choi YJ. Establishment of a 2-D human urinary proteomic map in IgA nephropathy. Proteomics 2006; 6: 1066-1076

25. Hamada S, Satoh K, Hirota M, Kanno A, Ishida K, Umino J, Ito H, Kikuta K, Kume K, Masamune A, Katayose Y, Unno M, Shimosegawa T. Calcium-binding protein S100P is a novel diagnostic marker of cholangiocarcinoma. Cancer Sci 2011; 102(1): 150-156

26. Veenstra TD, Conrads TP, Hood BL, Avellino AM, Ellenbogen RG, Morrison RS. Biomarkers: mining the biofluid proteome. Mol Cell Proteomics 2005; 4: 409-418

27. Zhou M, Conrads TP, Veenstra TD. Proteomics approaches to biomarker detection. Brief Funct Genomic Proteomic 2005; 4: 69-75

28. López JL. Two-dimensional electrophoresis in proteome expression analysis. J Chromatogr B Analyt Technol Biomed Life Sci 2007; 849:190-202

29. Taylor RC, Coorssen JR. Proteome resolution by two-dimensional gel electrophoresis varies with the commercial source of IPG strips. J Proteome Res 2006; 5: 2919-2927 